\title{
O possível cenário das compras coletivas no e-commerce brasileiro
}

\author{
The possible scenario of shopping in \\ collective brazilian e-commerce
}

Priscilla Diniz Corrêa ${ }^{1}$

\section{Resumo}

Os sites de compras coletivas transformaram o modo de consumo. O ambiente web é a mais nova forma de compra dos brasileiros, que proporciona praticidade e preço baixo. O consumidor se mostra cada vez mais fascinado por promoções, assim como mais conscientes de seus poderes. Nesse contexto, o presente artigo disserta sobre o consumo e o consumidor online no Brasil. Apresenta o case ClickOn, proporcionando uma visão prático-descritiva de um site de compras coletivas e uma pesquisa aplicada junto a consumidores que apresentam como resultado suas experiências e desejos ao referido mercado, disponibilizando, ao final, um cenário para o futuro desse modelo de negócio. Os dados apontam que houve declínio no mercado devido às reclamações por parte dos consumidores, mas o cenário apresenta-se positivo para continuação do modelo de negócio, com a necessidade de mudanças.

Palavras-chave: Internet. Comércio eletrônico. Consumidor web. Compras coletivas.

\begin{abstract}
The collective shopping sites have transformed the mode of consumption. The web environment is the newest form of purchases of Brazilians that provides convenience and low price. The consumer is becoming increasingly fascinated by promotions, as well as more aware of their powers. In this context, this article discusses about consumption and online consumer in Brazil. Introducing the ClickOn case, providing a practical view-descriptive of a group buying site and applied research with consumers who have as a result of their experiences and desires to that market. Providing, at the end, a scenario for the future of this business model. The data show that there was a decline in the market due to complaints by consumers, but the scenario is positive for continued business model, with the need for change.
\end{abstract}

Keywords: Internet. Ecommerce. Consumer web. Collective purchasing.

1 Graduada em Publicidade e Propaganda pelo Centro Universitário de Brasília- UniCEUB. Atualmente, gerente de contas na Multiplus Fidelidade. Trabalhou no site de compras coletivas ClickOn como gerente comercial. E-mail: pri@pridiniz.com.br. 


\section{Introdução}

O presente artigo aborda o ciclo de vida dos sites de compras coletivas no Brasil e um possível cenário futuro desse modelo de negócio.

$\mathrm{Na}$ última década, o Brasil passou por mudanças estruturais econômicas que geraram estabilidade e crescimento. Com a geração de mais empregos, houve aumento da renda e do crédito ao consumidor, permitindo a expansão do poder de consumo do brasileiro. (MANSUR, 2012). Paralelamente a esses indicativos econômicos, de acordo com o Instituto Brasileiro de Opinião e Estatística (IBOPE), o acesso à internet teve significante crescimento, chegando ao número de 85,3 milhões de pessoas com acesso no Brasil, no terceiro trimestre de 2012 (INSTITUTO BRASILEIRO DE OPINIÃO E ESTATÍSTICA, 2012). Os fatores citados anteriormente contribuíram positivamente para a promissão do $e$-commerce no mercado brasileiro.

Com o fortalecimento do comércio eletrônico, surgiram novos formatos de compra na internet, dentre eles, o inovador modelo de compras coletivas, que ganhou muita popularidade nos últimos três anos e atraiu a atenção de grandes e pequenos investidores por todo o mundo. Essa nova modalidade de e-commerce, que tem como objetivo vender produtos e serviços para um número mínimo pré-estabelecido de consumidores por oferta, conseguiu revolucionar e impulsionar o comércio eletrônico no Brasil.

Os sites de compras coletivas entraram no mercado brasileiro em 2009, com o intuito de atrair consumidores pelas pechinchas anunciadas e atrair parceiros com a promessa de divulgação da marca. De acordo com Araujo (2010):

O objetivo dos empresários ao anunciar suas empresas nesses sites não é o lucro e sim a conquista de novos clientes e divulgação da marca, tendo a oportunidade de atrair consumidores até $\mathrm{o}$ estabelecimento e vender outros produtos além dos ofertados.

Em termos gerais, o sistema de compras coletivas foi considerado benéfico e uma excelente oportunidade de negócio para todos os envolvidos. Sendo assim, logo no início, o sistema parecia tão simples que vários outros sites apareceram e transformaram esse modelo de negócio no fenômeno do e-commerce em 2010. Em dezembro, já havia mais de 400 sites de compras coletivas em funcionamento ou em fase de implantação no Brasil: vitória do empreendedorismo brasileiro, que demonstrou agilidade na resposta por novas demandas. (VALLE, 2011).

Hoje, passados quase três anos da entrada desse mercado no Brasil, a realidade já é outra. Dados alertam sobre o crescimento do número de reclamações contra sites de compras coletivas: mais de $400 \%$ no primeiro semestre de 2012 em comparação ao mesmo período do ano anterior resultaram na aplicação de $\mathrm{R} \$ 250 \mathrm{mil}$ em multas, provocando assim, a solicitação de algumas empresas no sentido de assumirem um compromisso de melhoria nos serviços. Em novembro de 2012, a Fundação de Proteção e Defesa do Consumidor (PROCON) autuou os sites Groupon, ClickOn e Peixe Urbano, os três maiores do segmento, por registrar 767 queixas. $\mathrm{O}$ ano de 2011 foi fechado com 1.690 reclamações, mas em 2012 ultrapassaram 2.000. (DESTAK, 2012). O desafio agora é tentar manter-se no mercado, pois com tanta reclamação, a credibilidade vem caindo.

A grande pergunta é: $\mathrm{O}$ que os sites de compras coletivas devem fazer para se manter no mercado brasileiro?

Este artigo tem como objetivo geral apresentar o e-commerce no Brasil e mostrar o comportamento dos consumidores desse mercado, com ênfase nos sites de compras coletivas.Tem como objetivos específicos utilizar o case do site ClickOn como objeto de estudo para entender o ciclo de vida dos sites de compras coletivas, com a finalidade de conhecer as principais reclamações, desejos, anseios e expectativas dos consumidores. Objetiva, também, propor, à luz do embasamento teórico e com vistas aos dados de mercado, soluções para um possível cenário futuro dessas empresas.

Como método de pesquisa, o estudo utiliza a pesquisa bibliográfica, estudo de caso por análise de dados obtidos em uma convenção interna do site ClickOn, que expõe seu ciclo de vida. Também utiliza pesquisa de campo realizada com 1.200 pessoas aleatórias, aplicada pela rede social Facebook e respondida por sessenta e cinco usuários, residentes em Brasília, de escolaridade a partir do ensino médio, aplicada no período de 10 a 15 de maio de 2013, contendo treze questões que visam conhecer melhor esse consumidor. Implementa, como instrumento para coleta de dados, um questionário criado pelo Google docs. Os resultados são analisados por meio de gráficos gerados após resultado. Logo, trata-se de uma pesquisa qualitativa, do tipo exploratória.

De acordo com Gil (1991, p. 43)

A pesquisa exploratória tem como propósito 
proporcionar maior familiaridade com o problema visando torná-lo explícito ou a construir hipóteses. Envolve entrevistas com pessoas que tiveram experiências práticas com o problema pesquisado, análise de exemplos que estimulem a compreensão e levantamento bibliográfico.

Dados citados anteriormente apontam um declínio no mercado, fatos que justificam a importância deste estudo. Para os empresários, estar ciente das variáveis de mercado é um assunto primário quando se trata de investimentos. Conhecer o seu consumidor, ter alternativas, planos de inovação e consistência é o que faz uma empresa continuar atrativa a investimentos e com projeção de crescimento.

Para a academia, este estudo destaca a importância de estar sempre atualizado sobre o comportamento do consumidor e as novas tendências, principalmente quando se trata de um assunto tão dinâmico e variável como a internet.

Como estrutura apresentam-se, bibliograficamente, os avanços do e-commerce no Brasil, o comportamento do consumidor na web e o propósito dos sites de compras coletivas. Após pesquisa bibliográfica, busca-se em campo, conhecer o ciclo de existência e o presente momento dos principais sites, assim como o ponto de vista de seus consumidores.

\section{Consumo e consumidor online}

Em um mundo globalizado, onde a tecnologia se tornou um fator relevante na vida pessoal e profissional das pessoas, compreender os caminhos da internet e os negócios digitais faz-se importante para melhor entendimento das mudanças na forma de se comunicar, comprar e interagir.

Ao se conectar a um computador, pode-se ter acesso ao mundo. A internet é formada pelas centenas de redes de computadores conectadas em diversos países para compartilhar a informação, ou seja, é uma rede mundial de computadores. (PINHO, 2000).

A integração de serviços como o correio eletrônico, listas de discussão e comércio online são méritos do rápido desenvolvimento da internet, que atualmente envolve milhões de pessoas, instituições e empresas em todo o mundo, tornando o comércio eletrônico a "estrela" do mundo virtual.

Hoje, no Brasil, o total de pessoas com acesso à rede chegou a 85,3 milhões no terceiro trimestre de 2012. Esse número considera usuários a partir de 16 anos de idade com acesso a qualquer ambiente-domicílio, trabalho, escolas, lanhouse e outros locais, o que representa um crescimento de 8,8\% sobre os terceiro trimestre de 2011. Considerando apenas os usuários com acesso à internet em domicílios, o número é de 69,5 milhões de usuários, um crescimento ainda maior, de $16 \%$ sobre o mesmo trimestre de 2011. (INSTITUTO BRASILEIRO DE OPINIÃO E ESTATÍSTICA, 2012).

O Brasil tem $40,7 \%$ de internautas entre a população, de acordo com os dados consolidados pelo Programa das Nações Unidas (PNDU), apresentando assim, taxa maior do que a média mundial que é de 30\%. (PROGRAMA DAS NAÇÕES UNIDAS, 2012).

As empresas logo perceberam ser uma área lucrativa e passaram a investir significantemente no setor de vendas pela internet. Considerado uma fonte de comodidade e de conforto, o e-commerce é definido por Ulbrich (2000, p. 16) como "[...] a atividade desenvolvida na internet, com a utilização de ferramentas eletrônicas e tecnologias emergentes, que tem por objetivo principal a negociação de compra e venda de bens e serviços".

Ouve-se muito sobre comércio eletrônico. Kalakota e Robinson (2002, p. 24) dizem que:

[...] não se trata apenas de transações de comércio eletrônico ou compras e vendas pela Internet. É uma estratégia global de redefinição dos antigos modelos de negócios com auxílio de tecnologia, para maximizar o valor do cliente e dos lucros.

Essa não é mais uma tendência, e sim, uma revolução no mundo dos negócios que já afeta a maneira de viver, de trabalhar e de se divertir, prometendo se fazer ainda mais presente.

Com o surgimento do e-commerce e de suas vitrines virtuais, o consumidor observa e compra pela internet cada vez mais: surge um novo cenário com mudança de meio escolhido para compra, que se deve ao número crescente de usuários na rede, dispostos a adquirir.

Vale ressaltar que somente no ano de 2012, o e-bit ${ }^{2}$ consolidou o desempenho do comércio eletrônico digital em um faturamento de 49,7 bilhões de reais, abrangendo vendas de passagens aéreas, turismo, marketplaces - locais destinados ao comércio de bens e serviços, como o site Mercado Livre em sites de compras coletivas. Além

2 E-bit é um site de certificação que reflete a satisfação de consumidores que compram em lojas online cadastradas. 
das vendas de bens de consumo, que somaram 22,5 bilhões, estima-se que o ano de 2013 apresente resultados melhores que 2012, em virtude da retomada do crescimento econômico e da aceleração das vendas de dispositivos móveis como tablets e smartphones. Dados também apontam que 42,2 milhões de consumidores já realizaram uma compra online no Brasil, e para este ano de 2013 esse número deve saltar, superando 50 milhões de pessoas. (EXAME.COM, 2013).

Para o consumidor, o e-commerce permite, sem sair de casa, acesso às informações e a bens infinitamente mais numerosos do que se tivesse que se deslocar fisicamente para obtê-los; e também, economia, uma vez que produtos adquiridos na internet, na maioria das vezes, têm preços menores do que os praticados nas lojas físicas e oferece, ainda, conveniência e velocidade. Podem-se efetuar transações 24 horas por dia e acesso ao mundo. A interatividade e a praticidade do comércio eletrônico conquistaram os consumidores.

Para as empresas, o e-commerce é uma forma moderna de trabalhar, por se tratar de um serviço que pode ser acessado por qualquer pessoa, em qualquer lugar do mundo. É uma forma de marketing que pode acelerar a forma de divulgação de um produto e romper fronteiras, sendo ideal para pessoas que desejam desenvolver negócios. Entre os benefícios estão: redução de custos, melhoria da organização, dos processos de negócios e interatividade (CASTRO, 2011).

Segundo o site e-commerce. org, o e-mail marketing se destaca com uma das principais ferramentas para visibilidade do consumidor, aumento das vendas online, geração de tráfico e relacionamento. As principais razões são:

- Agilidade: o e-mail é uma ferramenta ágil, pois um simples click, dispara o envio de milhares de e-mails em segundos para os destinatários;

- Mensurabilidade: medir o retorno do e-mail marketing é fácil, fornecendo estatísticas de quantas pessoas receberam, quantas clicaram em um link, visitaram o site e efetivaram a compra. Também fornece dados de quantas pessoas não desejam mais receber sua comunicação para exclusão da lista e diversas outras informações;

- Interatividade: a abertura do e-mail direcionada a um link possibilita o destinatário realizar uma ação, como visitar um site ou solicitar a exclusão da lista; e

- Alta taxa de resposta: campanha de e-mail marketing opt-in, onde as pessoas consentem em receber sua comunicação e fornecem o seu endereço de e-mail: tem altos índices de retorno. O baixo índice de retorno acontece, quando existe o SPAM, que é a prática de se fazer e-mail marketing junto a destinatários que não autorizaram o recebimento de e-mails; infelizmente, trata-se de algo comum. (E-MAIL, 2013).

Toda essa mudança na postura do comércio revela um consumidor mais consciente e conectado com seus direitos e desejos.

Mendes (2010) diz que a internet precisa ser ativada por pessoas que utilizam o meio on-line para se agruparem em comunidades virtuais e que essa noção de comunidades tem sido o coração da internet. Foi quebrada a aproximação geográfica que era necessária para identificar comunidades: elas passaram a existir no ambiente on-line, mas, ainda assim, como as outras, sua formação continua se estabelecendo a partir de agrupamentos sociais com base em afinidades.

Nessas comunidades há troca de conhecimentos; exemplo disso é a compra on-line, na qual os internautas usam as mídias sociais para pesquisar se os produtos que pretendem adquirir estão de acordo com seu desejo. $\mathrm{O}$ usuário encontra informações por meio de redes sociais, blogs, indicação de amigos e sites especializados, dentre outros, tornando a compra web diferente do ato em uma loja física, onde há sempre um vendedor tentando impor a venda de um produto. Ele desfruta de milhares de fontes de consulta para comprar o que ele realmente precisa.

Segundo Torres (2009, p. 358)

Os brasileiros passam três vezes mais tempo na Internet do que na televisão e trocam informações sobre produtos, serviços e empresas antes de decidir qualquer compra. Estão muito mais críticos e seguros de si, pois entendem o poder que têm.

De simples receptor, o consumidor passa a informante sobre os produtos e serviços que utiliza, estando presente na comunicação de muitos, para muitos: o processo em que muitos falam e muitos ouvem. Isso gera poder dentro do mercado, pois o consumidor passa a opinar sobre as marcas, produtos e divulgar suas experiências com as empresas, sejam elas negativas ou positivas. Da mesma forma que divulgam suas experiências on-line, eles buscam informações na internet sobre determinado produto ou serviço e, como lembra Torres (2009, p. 357), "[... ] confiam mais nos amigos e vizinhos na hora de comprar ou recomendar um produto ou serviço. $\mathrm{O}$ boca a boca anda na velocidade da luz". 
Com a facilidade de trocas de informações no universo online, o foco das empresas, que outrora era apenas vender, passa agora a ser também de se relacionar e manter diálogo para estreitar relacionamentos. São diversas as ferramentas disponíveis para essa interação, entre elas, as redes sociais como o Facebook, o Twitter, o Orkut e os Blogs.

Sobre esse novo comportamento do consumidor online no Brasil, Torres (2009, p. 358) diz:

O consumidor on-line no Brasil representa as classes A, B e C, acessa pelo menos uma hora a internet toda semana. Ele busca diversão, relacionamento e informação, usa as ferramentas de busca, participa de redes sociais e lê muito.

Uma pesquisa realizada pela $H i$-Mídia ${ }^{3}$ e pela M.Sense $e^{4}$, em abril de 2012, com 1.214 entrevistadas nas cinco regiões brasileiras, traçou o perfil do consumidor on-line brasileiro: o estudo indica a internet como grande influenciadora na hora decisiva do consumidor comprar, e que $77 \%$ dos entrevistados afirmam a busca por informação sobre produtos em sites de busca, redes sociais, blogs ou sites institucionais das empresas.

$\mathrm{O}$ estudo aponta também que os consumidores on-line das classes $\mathrm{C} / \mathrm{D} / \mathrm{E}$ já estão mais presentes com 93\% dos entrevistados, contra 90\% dos pertencentes às classes A/B. Revela que os consumidores mais ativos estão entre 25 a 49 anos e que a região campeã entre os entrevistados é o Nordeste, com 96\% dos entrevistados comprando on-line contra $92 \%$ das regiões Sudeste, Sul e Centro-Oeste/Norte. Os campeões são os homens com $94 \%$ contra $91 \%$ das mulheres fazendo compra online

A principal vantagem de se comprar pela internet para $68 \%$ dos internautas é o preço, enquanto 56\% levam em consideração a comodidade. Também foram citados pelos entrevistados os principais motivos para se comprar online: a variedade dos produtos, facilidade de pagamento, busca de informações e dicas. A pesquisa apontou que, praticamente, todos os consumidores comparam preços na internet antes de fazer suas compras, independentemente se serão realizadas em lojas físicas ou online. (E-COMMERCE, 2012b).

De acordo com um estudo realizado pela Exact Targer nos Estados Unidos e na Europa, 40\% dos consu-

3 Empresa especializada em venda de mídia online com foco em segmentação e desempenho.

4 Empresa especializada no estudo do mercado digital. midores online procuram mais informações em redes sociais e em sites de compras coletivas ao receber um e-mail marketing. Foram identificados também diferentes tipos de consumidores online, após analisados os critérios de desempenho em mídias sociais considerando diferentes idades e níveis de renda. A pesquisa traça os doze perfis mais comuns de consumidores on-line, a saber:

- Círculo de confiança: são os não interessados em desenvolver novos relacionamentos além dos familiares e amigos. Eles costumam não gostar de e-mails promocionais e de mensagens enviadas por empresas;

- Cautelosos: são muito ativos nas redes sociais e exigem privacidade sobre as informações que compartilham com suas marcas favoritas. São seletivos com quem se comunicam e com o tipo de informação que compartilham na web;

- Candidato à informação: recorrem à web em busca de informações de terceiros sobre produtos que já têm em mente. Para as marcas, ter um bom conteúdo no seu perfil é a melhor maneira de chamar sua atenção;

- Entusiastas: são muito ativos no uso de tecnologia e procuram manter contato com pessoas de interesses semelhantes. Usam o e-mail e mensagens em redes sociais para se comunicar. Gostam de ser os primeiros a receber informações das marcas, mas exigem conteúdos interessantes e de qualidade;

- Caçadores: procuram por descontos e ofertas em todos os canais disponíveis: e-mail, redes sociais;

- Compradores: não compram apenas pela internet, mas quando estão on-line aproveitam para comprar; gostam de ter certo relacionamento com a marca através de e-mail e redes sociais. Estão interessados na qualidade e no preço, portanto, pesquisam muito em sites de lojas antes de comprar;

- Viciados em notícias: têm a internet como fonte de informação. Costumam publicar artigos e gerar conteúdos para mídias sociais. São mais propensos a ler artigos sobre produtos do que outros grupos;

- Jogadores: têm como foco tudo que se direciona para videogames. Usam as redes sociais apenas para jogar e compartilhar experiências, não se interessando em seguir marcas;

- Borboletas sociais: são blogueiros ativos que têm como interesse fazer novos contatos e amigos. Preferem receber e-mails, a trocar mensagem no Facebook ou Twitter;

- Negociadores: procuram a internet para conta- 
tos profissionais, tendências e oportunidades de emprego. Usam e-mail com frequência, não em busca de ofertas, pois não costumam seguir marcas na internet;

- Amplificadores: são mais fiéis à marca do que consumidores médios e levam as interações sociais a sério. São frequentes no uso do Twitter e Facebook; e

- Livro aberto: estão sempre dispostos a divulgar suas experiências e conhecer pessoas para compartilhá-las, por isso, podem ser os maiores defensores ou detratores das marcas. São os maiores responsáveis por comentários inadequados. (E-COMMERCE, 2011).

A necessidade das empresas estarem conectadas ao seu público, hoje, é indispensável e traçando um perfil do seu consumidor é possível fazer um trabalho segmentado, contribuindo para atingir os objetivos de comunicação. Ir muito além do simples fato de vender e atender todas as necessidades do consumidor faz com que a empresa crie fortes laços com os seus clientes.

A comunicação e o diálogo on-line estreita os laços com a capacidade de acelerar as questões de atendimento ao cliente. Consumidores satisfeitos disseminam suas experiências a familiares e a amigos, tornando-se lucrativos.

Uma recente pesquisa, realizada neste ano de 2013, revela um fator importante sobre o comportamento do consumidor online: o excesso de e-mails incomoda e é a principal causa dos cancelamentos por parte dos consumidores. Segundo Martins (2003), escritor de um artigo sobre esta pesquisa,

\begin{abstract}
[...] descontos e promoções são as principais razões para o cliente cadastrar seu e-mail para o recebimento de informativos $(83,5 \%)$. Em seguida, aparece a fidelidade à marca $(7 \%)$, o interesse por atualizações da loja $(6,4 \%)$ e, por último, a participação nas pesquisas da loja $(3,1 \%)$.
\end{abstract}

Nesse ambiente, em que a internet está disponibilizando a satisfação para consumidores e onde tudo se modifica rápido, surgiram as compras coletivas, um dos modelos de negócios mais lucrativos da história da rede.

\section{Os sites de compras coletivas}

A modalidade de e-commerce compras coletivas tem como objetivo vender produtos e serviços para uma quantidade mínima de consumidores estabelecida, possibilitando grandes descontos em produtos e serviços. Vende-se um mesmo produto para o maior número de pessoas em curto espaço de tempo, para proporcionar o menor valor de venda possível. Os descontos sempre oscilam entre $50 \%$ e $90 \%$. Depois de publicar e divulgar a oferta, se o número mínimo de compradores estabelecido for alcançado, todos os compradores recebem o cupom da oferta para utilizar, caso não seja, a compra não é efetivada. A publicação das ofertas acontece principalmente por e-mail marketing e redes sociais, utilizada para disseminar as ofertas, e assim, obter o número necessário de compradores para que a transação seja concluída. (E-COMMERCE, 2010).

Segundo Felipine (2011), a definição do que seja compras coletivas pode variar de acordo as partes envolvidas. Para os internautas, o sistema de compras coletivas é uma forma de adquirir produtos e serviços a preços mais acessíveis. Já para o comerciante, é uma ferramenta de marketing que, com rapidez, possibilita trazer um grande número de compradores para o seu estabelecimento. Finalmente, para os empreendedores, é um negócio a ser explorado.

Os sites tiveram início em novembro de 2008, nos Estados Unidos por Andrew Mason, um jovem de apenas 29 anos. A ideia surgiu quando ele teve dificuldades em uma negociação e considerou a possibilidade de reunir um grupo de pessoas interessadas em um mesmo produto para aumentar o poder de barganha. Daí, surgiu o Groupon, pioneiro que teve um crescimento estratosférico, alcançando um valor de mercado na casa dos bilhões em apenas 16 meses após sua fundação. (ENTREVISTA, 2010).

No Brasil, em 2010, Julio Vasconcelos, observando o sucesso nos Estados Unidos, achou que tinha tudo para dar certo no Brasil e fundou o Peixe Urbano, primeiro site de compras coletivas do país, lançado oficialmente em 10 de março de 2010 no Rio de Janeiro.

No seu primeiro ano de atuação no Brasil, os sites de compras coletivas já foram considerados sucesso absoluto. Em outubro de 2010, dados do Serasa revelaram que o crescimento dos sites desse segmento foi exorbitante: de $13.000 \%$ desde abril do mesmo ano, tendo como líder o Clube Urbano, seguido pelo Peixe Urbano. O Clube Urbano foi adquirido pelo Groupon logo no seu início. (VELOSO, 2010).

As principais características desse negócio inicialmente eram: foco no serviço, número mínimo de compradores, apenas uma oferta por dia, grandes descontos, 24 a 48 horas para o fim da oferta, bônus e premiações para usuários que indicassem novos clientes.

Em ascensão e com destaque na mídia, as compras coletivas no Brasil chegaram à marca de R\$ 500 milhões, 
faturados em 2010, com pouco mais de nove meses de operação no Brasil, sendo considerada a nova febre da internet brasileira. (FUSCO, 2010).

A quantidade de sites cresceu excepcionalmente: após apenas dez meses da entrada do pioneiro Peixe Urbano no mercado brasileiro, já existiam 1025 sites em funcionamento na rede. (BOLSA DE OFERTAS, 2011). Os principais fatores para que isso acontecesse deram-se pelas baixas barreiras de entrada, lucratividade e grande aprovação do mercado.

Ainda em crescimento, no seu segundo ano de existência, o setor de Compras Coletivas cresceu 644\% em relação a 2010, movimentando $\mathrm{R} \$ 1,6$ bilhão no Brasil, segundo relatório do indicador InfoSaveMe em parceria com a e-bit. Resultado esse que corresponde a 9\% do faturamento total do e-commerce brasileiro em 2011, que foi de $\mathrm{R} \$ 18,7$ bilhões, o que significou para alguns, uma consolidação do setor no mercado brasileiro. (E-COMMERCE, 2012a).

Passados quase dois anos do segmento no Brasil, posterior ao "boom" do primeiro momento e aos números exorbitantes de faturamentos atingidos, os sites de compras coletivas continuaram em evidência na mídia, agora, não somente por um lado positivo.

Foram detectados grandes problemas, sendo eles: superlotação dos estabelecimentos, dificuldade de agendamento, prazo de validade dos cupons, descrições ruins, incompletas e entregas ineficientes. Esses problemas geraram muita frustração para os consumidores e muitas reclamações.

Segundo matéria publicada, só em 2011, foram registradas 45.898 queixas em um único site de reclamações pela internet, número seis vezes maior do que no ano anterior. A notícia cita: "Facilidade, comodidade e desconto. Uma mistura tentadora para o consumidor, mas, como diz o ditado, o barato às vezes sai caro." (MOREYRA, 2012).

No segundo semestre de 2012, revistas e jornais dão destaque a notícia anunciada pelo Procon de que as reclamações contra sites de compras coletivas subiram $400 \%$ em comparação com o mesmo período de 2011, autuando os sites a assumirem um compromisso de melhorias em seus serviços prestados. (VEJA, 2012).

Essas notícias e as más experiências vividas por usuários acabaram afastando novos consumidores e criando uma má fama aos sites, fator esse que contribuiu para a desaceleração do mercado.
Paulo Arthur Góes, diretor-executivo do Procon, disse ao Jornal Folha de São Paulo que "[...] o aumento das reclamações se deve ao crescimento do setor: com o aumento da demanda, vários sites com esse tipo de serviço surgiram, mesmo estando despreparados e sem estrutura para isso." (PENATTI, 2012).

O número de sites em funcionamento diminuiu, quando em 2011 chegaram a existir 1025 sites, no segundo semestre de 2012 houve redução para 800 em funcionamento. Guilherme Wroclawski, sócio fundador do portal SaveMe, agregador de ofertas de sites de compras coletivas, explica a queda do número de sites no ar: "Alguns aventureiros entraram no mercado achando que o negócio era só vender cupons. No entanto, o mais importante é a experiência de uso do consumidor, possuir bons parceiros e oferecer um pós-venda de qualidade. Por isso, os que não se adaptaram ou não entenderam a dinâmica fecharam".

Muitos fecharam as portas por falta de estrutura e de planejamento, sem disposição de recursos para investimentos; e os que se mantiveram estão se adaptando para sobreviver à acomodação do mercado. Somente os grandes devem sobreviver e aqueles que melhor se adaptarem ao mercado.

\section{Case clickon}

Com intuito de entender os processos internos dos sites de compras coletivas, apresentam-se dados obtidos em uma convenção interna do site ClickOn, apresentada pela atual diretora Karina Rocha, que expõe o ciclo de vida e os principais problemas enfrentados atualmente pelo site.

A ideia do site ClickOn nasceu em dezembro de 2009, quando um dos sócios investidores conhece o modelo de negócio compras coletivas em uma viagem aos Estados Unidos. Interessado, traz a novidade para o Brasil e apresenta o negócio aos futuros sócios, que acreditam no potencial das compras coletivas e apostam na novidade. Sendo assim, decidem implantar o mesmo modelo no site ClickOn. Contam inicialmente com a ajuda de fortes incentivos, criando o site com um investimento de 17 milhões de reais. Os investidores, também sócios, são os alemães Klaus Hommels e Oliver Jung, e a A5 Investimentos, do veterano do e-commerce brasileiro, Paulo Humberg.

Com estrutura formada primeiramente por três sócios executivos, Marcelo Macedo- CEO, João Ramirez- 
Diretor de Marketing, e Roberto Meira- Diretor Comercial, o site entra no ar em 10 de maio de 2010, em São Paulo, e consegue atingir o número de 100 mil usuários cadastrados e nenhuma oferta sem ser ativada em apenas duas semanas de existência.

$\mathrm{O}$ crescimento absurdamente rápido do segmento e a "febre" dos sites de compras coletivas fizeram o ClickOn tornar-se referência em vendas de produtos e serviços com descontos naquele momento.

Devido à rápida expansão, a sede que era em uma microssala, com apenas quatro funcionários, mudou-se para uma sede de três andares em um prédio comercial no Jardim Paulista, onde está localizada até hoje.

A estrutura passou a ser formada por uma equipe com mais de 100 funcionários divididos nos setores de marketing - responsável pela divulgação do site e ampliação da base; equipe comercial - responsável pela prospecção de clientes e fechamento de ofertas; operacional - responsável pela criação do layout e aprovação de ofertas juntamente ao parceiro; planejamento estratégico - posicionamento de grade de ofertas; TI - suporte a toda demanda operacional do site; e SAC - responsável pelo report aos consumidores.

Atingindo a marca de um milhão faturado no seu primeiro mês, decidiu-se investir em crescimento, contratação de equipe e abertura de praças. A estratégia era colocar no ar tudo que pudessem vender.

Após sete meses no mercado, com uma média de 180 funcionários, uma base de 900.000 mil novos usuários e um faturamento de 11 milhões por mês, acreditava-se estar no caminho certo e se deu continuidade à busca de faturamento a qualquer custo. No momento, a mídia era positiva e o mercado reagia bem, o que ajudou bastante nos bons resultados.

As conquistas iam crescendo e, em 2011, o ClickOn conseguiu bater o recorde da quantidade de cupons vendidos, com uma oferta do cinema Kinoplex, em que a venda foi de 102.462 cupons de ingressos para cinema com $75 \%$ de desconto. No mesmo ano também atingiu o maior faturamento, com 2,7 milhões faturados em uma única oferta de pacote para Disney. Mas, e a logística para entregar tanta demanda?

O fundador e diretor do site no momento citado acima, Marcelo Macedo (2013) declarou:

O modelo me surpreendeu com a complexidade. No início pensei: vender cupons não tem logística, somente um desafio comercial. Como não tinha um exemplo com vasta experiência no mercado - como o amazon para ecommerce - parece que todo mundo tinha que aprender o que significava administrar milhares de parceiros, consumidores, cupons junto com esse alto crescimento.

Em abril de 2011 o Grupo Mosaico - grupo de investidores de internet da Rede Globo - comprou 40\% do site, sócio investidor que trouxe ainda mais força para empresa e algumas mudanças.

A atual diretora executiva Karina Rocha levantou um estudo interno que caracteriza a presente visão do site sobre o seu ciclo de vida, girando em torno da seguinte pergunta: será que foco total em crescimento e a busca a qualquer custo por faturamento seria o caminho certo?(ROCHA, 2013).

Segundo Karina, o site ClickOn caracteriza o seu primeiro ano de existência como um início de aprendizagem, crescimento e "febre".

O mercado já vinha sofrendo com reclamações, o site reclameaqui registrava uma média de 1500 reclamações mensais. O número de cancelamentos chegou a ser maior que o número de vendas em um mês, chegando a prejuízos de milhões. $\mathrm{O}$ faturamento bruto exorbitante que parecia atraente em um primeiro momento, começou a se mostrar ameaçador.

Caracteriza-se o segundo ano como um momento de "febre, gripe, tratamento" um momento com necessidade de consolidação.

Nesse momento o mercado estava em desaceleração, com baixa diferenciação dos players, altos números de reclamações no Procon e reclameaqui, falta de qualidade nos parceiros e serviços prestados, imagem negativa dos sites de compras coletivas e "spamização" do segmento.

Internamente os números assustavam. O faturamento médio estava baixo, pois com a veiculação de 1600 ofertas por mês divididas nas 42 cidades em que estava presente, o SAC registrava 50.000 contatos e as taxas de cancelamento, estornos de serviços e fraudes atingiam números recordes. Alguns parceiros não estavam cumprindo o acordo e oferecendo serviços de péssima qualidade, acarretando descontentamento em massa dos consumidores. Constatou-se então que era preciso mais eficiência e rentabilidade, pois a credibilidade estava ameaçada.

Foi então que vieram dois grandes desafios: o de sustentabilidade do negócio e da conquista de credibilidade. 
Karina (2013) destaca:

A proposta de valor para os nossos compradores precisa ser a melhor oferta com o melhor preço todo dia; segurança no processo de compra, um bom atendimento e intermediação com os parceiros. Um bom e seleto time comercial para mudar a perspectiva: escolhendo o parceiro certo, avaliando o histórico, formando ofertas legais, intervindo, ajudando e monitorando a prestação de serviços do parceiro.

Após a compreensão de que para se consolidar era necessário mudar, o site passou por processo de reestruturação e se mantiveram apenas as principais praças, reduzindo o quadro de funcionários e focando em qualidade, tendo crescimento de contratação apenas no setor do SAC.

O terceiro ano está sendo considerado como a ida ao caminho certo, em que medidas foram tomadas com foco em qualidade e inovação. As principais mudanças giram em torno de conseguir um diferencial competitivo, sendo eles: qualidade, maior cuidado na seleção e gestão dos parceiros, maior cuidado na montagem das ofertas, atendimento impecável ao consumidor, fidelização dos parceiros mais importantes e foco para garantir qualidade. Com atenção ao item inovação ofertaram-se catálogos de ofertas em diferentes categorias, possibilidade de busca no site, design mais clean e Premium, proximidade com os consumidores por meio das redes sociais e chat online no próprio site. (ROCHA, 2013).

Ao olhar para o seu passado, não tão distante, a empresa enxerga que os problemas enfrentados têm origem no início imaturo e desconhecido do seguimento, e a falta de conhecimento e de parâmetros tornou-se uma armadilha. $\mathrm{O}$ faturamento vinha fácil e se acreditava que podiam vender qualquer coisa a qualquer preço. A falta de credibilidade dos consumidores, hoje, tem como principal motivo, o mau atendimento oferecido por parceiros que não cumpriram com o acordo comercial.

Atualmente, após analisar os fatos, Karina (2013) acredita que o nome compras coletivas está queimado no mercado e criou uma nova estratégia que está sendo trabalhada em sigilo, para tornar a ClickOn na maior agência de experiências online do Brasil, deixando de ser um site de compras coletivas.

\section{0 consumidor}

Para melhor entender os desejos e as necessida- des dos consumidores de compras coletivas, coletam-se dados por meio de uma pesquisa exploratória aplicada por enquete criada e enviada a um grupo de 1.200 pessoas aleatórias no Facebook e respondida por 65 pessoas, analisando dados mediante gráficos gerados pelo Google Docs. Em nenhuma das perguntas fez-se obrigatória a resposta, ocorrendo de algumas questões não chegarem ao percentual de $100 \%$, assim como, também houve algumas questões com a liberdade de marcação em mais de uma opção, resultando em percentuais superiores a $100 \%$.

Dos entrevistados, todos residentes em Brasília, $75 \%$ são mulheres e $25 \%$ homens, em sua maioria de 18 a 35 anos, cursando ou formados no ensino superior. Desses, 77\% afirmam já terem comprado em sites de compras coletivas, contemplando a popularidade do modelo de negócio citada no embasamento deste estudo.

Figura 1- Frequência de compra

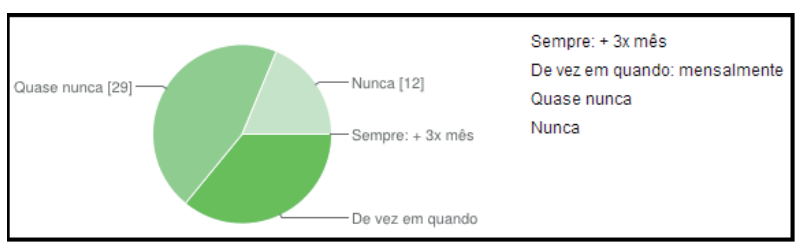

Fonte: elaborado pelo autor.

A grande maioria, 45\%, diz quase nunca comprar, e 35\% afirmam comprar de vez em quando. Analisando esse resultado, pode-se detectar que houve um interesse inicial no serviço, mas por algum motivo não se tornou um meio frequente de compra, apesar de dados expostos para este estudo afirmarem que as compras online vêm crescendo no Brasil. Nesse caso, destaca-se a importância de encontrar uma forma de retenção desses consumidores.

Figura 2- Principal razão para frequência nos sites de compras coletivas

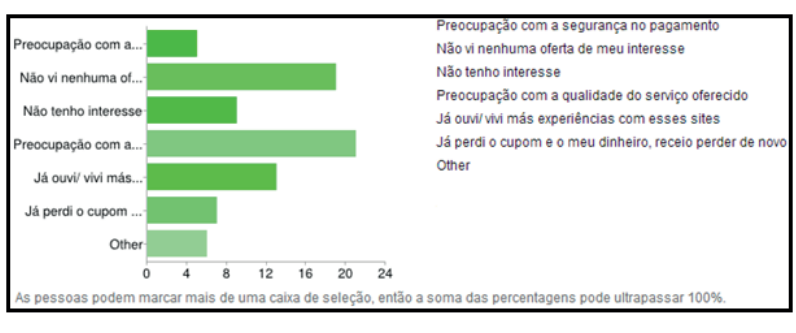

Fonte: elaborado pelo autor.

Apenas 9\% dos entrevistados alegaram estar preocupados com a segurança no pagamento, enquanto $37 \%$ acusam a preocupação com a qualidade do serviço; $33 \%$ a falta de ofertas interessantes e $23 \%$ por já terem vivido 
ou ouvido falar sobre más experiências nos sites como fatores para baixa frequência. Esses números caracterizam um consumidor mais exigente e preocupado com a qualidade do serviço oferecido, conforme já relatado no decorrer deste estudo, quando Torres (2009) afirma que os consumidores brasileiros trocam informações sobre produtos e serviços antes de decidir comprar e que estão muito mais críticos e seguros de si. Também convergem com os motivos apontados internamente pelo site ClickOn quando Karina Rocha, diretora do site, afirma a importância de se preocupar com a qualidade e acusa parceiros desqualificados como responsáveis pela perda de credibilidade do segmento. Esses resultados ressaltam a necessidade de qualificação dos parceiros e serviços oferecidos para se conseguir uma maior frequência dos usuários.

Figura 3 - Meio para se chegar às ofertas dos sites

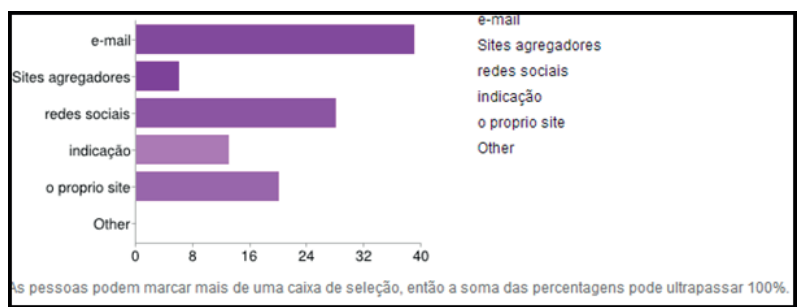

Fonte: elaborado pelo autor.

$\mathrm{O}$ resultado revela que $63 \%$ chegam às ofertas do site por meio do e-mail, o que consente com o artigo publicado pelo site e-commerce.org, citado no embasamento desta pesquisa, afirmando o e-mail marketing como principal ferramenta de visibilidade e divulgação para vendas. As redes sociais também se destacam como meio, representando $45 \%$ dos consumidores que podem ser os mesmos que usam o e-mail marketing, uma vez que essa questão contemplava mais de uma resposta por participante. Esses números revelam pessoas que se encaixam nos perfis de consumidores traçados pelo estudo realizado pela ExactTarget, exposto no decorrer deste artigo, podendo encaixar-se nos perfis de consumidores entusiastas, caçadores e compradores. Também se mostram disponíveis à fidelização quando $32 \%$ dizem entrar diretamente no site. Destaca-se a importância de administrar bem as ferramentas e-mail e redes sociais que já são bem aceitas pelos usuários.

Quando perguntado sobre a oferta ou o serviço específico mais buscado de acordo com a preferência, a maioria das respostas se baseou em gastronomia, entre- tenimento e viagens, afirmando o que foi citado no embasamento deste estudo, quando Torres (2009) diz que o consumidor online brasileiro busca diversão, relacionamento e informação.

Figura 4 - Existência de site favorito

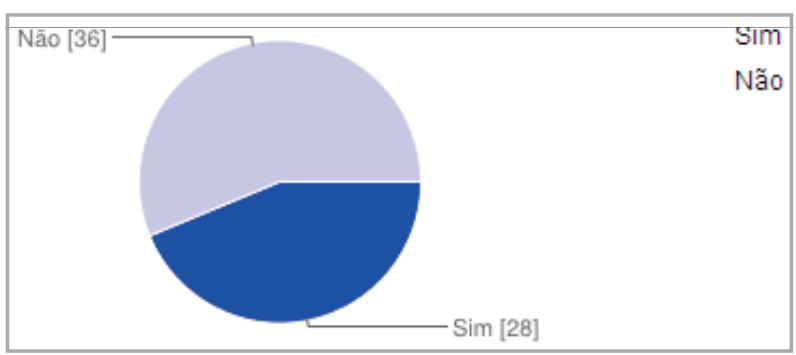

Fonte: elaborado pelo autor.

Dos entrevistados, 55\% alegaram não ter um site de compras coletivas favorito, mas o número de $43 \%$ que afirmam o contrário foi expressivo. Os sites relacionados como favoritos foram exclusivamente os maiores do segmento: Groupon, ClickOn e Peixe Urbano. Acredita-se que esses números sejam decorrentes do baixo número de players descritos como favoritos. Os sites podem conseguir destaque diferenciando melhor os players.

Figura 5 - Motivação para compra

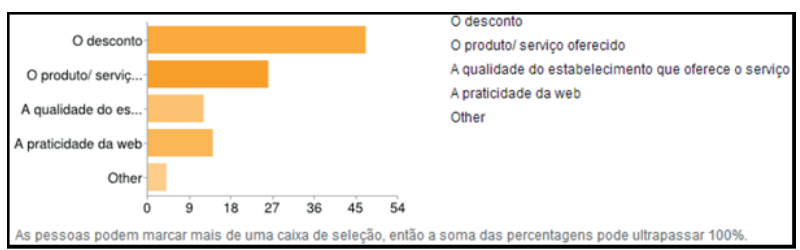

Fonte: elaborado pelo autor

Apenas $21 \%$ dos entrevistados se sentem motivados a comprar pela qualidade do estabelecimento que oferece o serviço, enquanto $81 \%$ alegam o desconto como principal motivador da compra, números que convergem com a afirmação descrita no embasamento deste estudo, no qual Felipine (2010) destaca que a principal vantagem para os internautas nas compras coletivas é a forma de adquirir produtos e serviços a preços mais acessíveis. E Felipe Martins (2013) apresenta dados de uma pesquisa na qual $83,5 \%$ dos clientes alegam como principal razão para cadastro de e-mail o recebimento de descontos e promoções. Esse segmento pode continuar tendo sucesso, enquanto conseguir combinar descontos e promoções com qualidade de serviço.

Figura 6 - Problema com as compras 


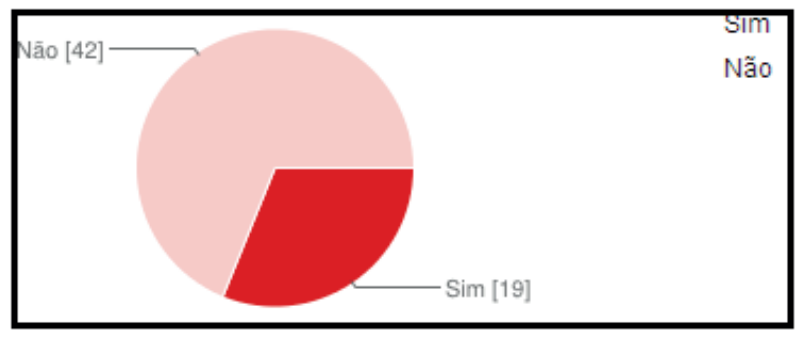

Fonte: elaborado pelo autor.

Dos participantes, 65\% afirmam nunca ter tido problemas em suas compras, enquanto $29 \%$ alegam isso. Esses 29\% insatisfeitos podem ser os responsáveis pelas mídias negativas aqui mencionadas e que foram o principal motivo para a falta de credibilidade atribuída às compras coletivas, confirmando, assim, o poder de influenciar e de informar dados aos consumidores a partir da internet. Destaca-se a importância que as empresas têm hoje de eficiência para resolver problemas e relacionamento com o seu consumidor.

Figura 7 - Definição dos problemas com as compras

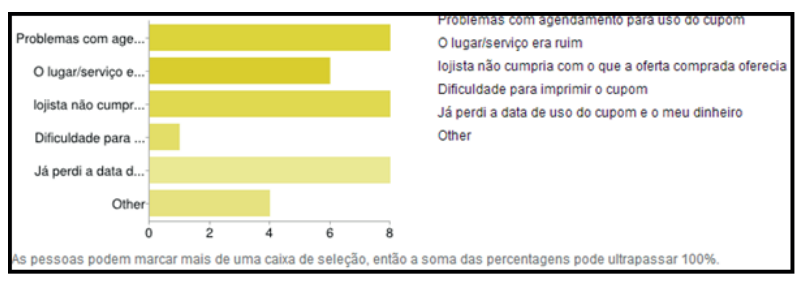

Fonte: elaborado pelo autor.

Dos 29\% que alegaram já ter tido problemas em suas compras, apenas 6\% apresentam dificuldade para impressão do cupom, relacionando os problemas vividos às dificuldades no agendamento; 44\%\%, falta de cumprimento das regras por parte dos lojistas; $44 \%$, lugar ou serviço ruim, com 33\%; e a perda do uso do cupom e do dinheiro, com $44 \%$. Esse resultado já era previsto, quando Karina Rocha, diretora do ClickOn, relata em entrevista descrita neste estudo que a falta de qualidade dos parceiros e de seus serviços prestados é o principal motivo para o descontentamento por parte dos consumidores. Esses dados alertam também para a preocupação em diminuir o noshow de cupons e a disponibilidade de uma ferramenta que facilite o agendamento.

Figura 8- Formas de uso do cupom

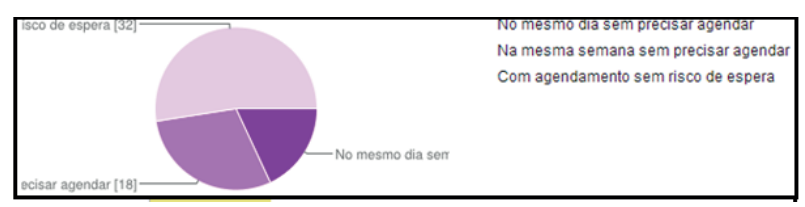

Fonte: elaborado pelo autor.

$\mathrm{O}$ resultado encontrado ressalta a diferente forma de pensar dos consumidores, visto que $45 \%$ preferem a liberdade de usar seu cupom no mesmo dia ou semana sem precisar agendar e 49\% alegam preferir não correr risco de esperar, optando pelo agendamento prévio como melhor opção. Esses dados indicam que a melhor forma seria dar mais de uma opção de usabilidade dos cupons, agradando a um maior número de clientes; $6 \%$ preferiram não opinar sobre o assunto.

Figura 9 - classificação das experiências vividas nos sites

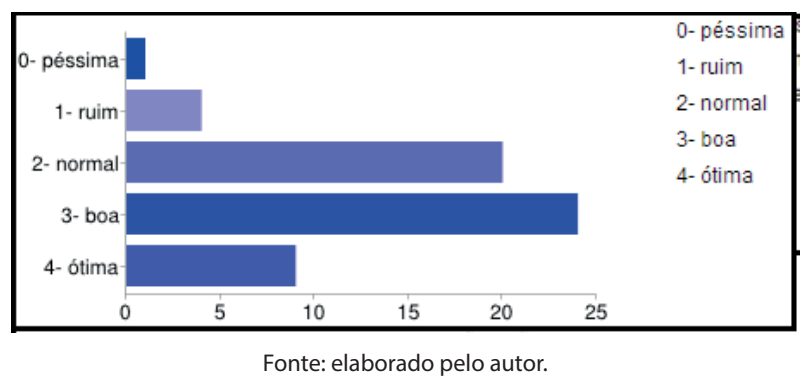

A grande maioria, 68\%, classifica as experiências vividas como boas ou normais, $14 \%$, como ótima e $8 \%$ dos entrevistados classificam suas experiências com ruins ou péssimas. Esses números somam-se aos 29\% que já tiveram problemas em suas compras. Faz-se necessária uma preocupação em melhorar as experiências vividas, aumentando o nível de satisfação para se conseguir mais credibilidade e, consequentemente, aumento da base de clientes satisfeitos.

Os pesquisados sugerem opções de melhorias para os sites, dentre elas, mais opções na forma de pagamento como débito em conta e boleto bancário; maior cuidado na escolha de parceiros, prezando em primeiro lugar a qualidade; cuidado em oferecer descontos reais; flexibilidade para o uso dos cupons; inovação e organização; atendimento rápido e prático aos consumidores, tirando dúvidas em tempo real; oferecer experiências inovadoras e dinâmicas; certificação de que a empresa tenha capacidade para atender a quantidade de cupons vendidos; cancelamentos com menos burocracia; maior variedade de ofertas; clareza nas regras; e agendamento fácil e rápido.

Após analisar dados levantados neste artigo, e de acordo com as respostas fornecidas pelos pesquisados, o cenário encontra-se favorável aos sites de compras coletivas. $\mathrm{O}$ e-commerce continua em ascensão e em crescimento no Brasil, e os consumidores web estão dispostos a comprar e ir em busca de descontos.

Acredita-se que os problemas enfrentados pelo segmento tenham sido decorrentes da falta de experiência e de antecedentes, consistindo em uma grande des- 
coberta para todos. Agora, com uma visão de mercado estabelecida, tendo como referência os acertos e erros já cometidos, cabe a cada site criar sua própria estratégia, para então tentar novamente revolucionar o mercado.

O primeiro passo de acordo com o case do site ClickOn, exposto no embasamento deste estudo, já está sendo feito: investir em melhorias voltadas ao consumidor, como canais de atendimento, maiores garantias e informações mais precisas e detalhadas nas ofertas.

Nesses três anos, os grandes players de compras coletivas conseguiram conquistar algo valioso: uma base de clientes opt-in- na qual os consumidores cadastraram seu e-mail espontaneamente com o intuito de receber descontos, principal atrativo do negócio; e assim deve permanecer.

Sugere-se que neste momento de estagnação, os sites estudem melhor essa base, segmentando esses usuários por bairro, idade, preferências de compras, dentre outros, para então, poder oferecer opções mais adequadas. Essa seria uma saída para minimizar o descontentamento que os consumidores têm ao receber muitas mensagens em sua caixa de e-mail, pois somente seriam enviados conteúdos e ofertas de interesse desse usuário. Esse estudo também pode favorecer a criação de catálogos de ofertas subdivididos por categoria, permitindo atender mais clientes e diluir o faturamento em maior número de ofertas que antes eram concentradas em poucas.

Outro caminho que se acredita favorável à adaptação é à segmentação: escolha de um nicho para atuação, algo que já é uma tendência e já tem alguns exemplos como o Hotel Urbano que anuncia hotéis em todo o Brasil, o Clube do Motel que atua em São Paulo ofertando apenas motéis da cidade, dentre outros. Segmentar pode ajudar na especialização do negócio, aumentando a qualidade do serviço e diminuindo o risco de reclamações em massa, o que caracteriza uma falha do modelo tradicional.

Como inovação, sugere-se uma adaptação desse modelo de compra para dispositivos móveis, em tempo real, possibilitando ao usuário comprar um cupom e utilizar minutos subsequentes. Com a utilização de aparelhos que disponibilizam a localização do usuário, podem-se criar alertas para ofertas próximas a ele, aumentando a possibilidade de adesão por parte do usuário.

É pertinente levar em consideração que, essencialmente, o sucesso do segmento deve combinar promoções e desconto com qualidade de serviço.

\section{Considerações finais}

As compras coletivas revolucionaram o e-commerce brasileiro. Desvendando um mercado sem precedentes, os sites seguidores do modelo inovador conquistaram rápida aceitação do consumidor brasileiro, atingiram números de faturamentos recordes, mas também enfrentaram sérios problemas com órgãos de defesa do consumidor e desaceleração do mercado imaturamente. Paralelamente, no meio em que se encontra, o comércio eletrônico no Brasil apresenta-se aquecido e em ascensão, com consumidores dispostos a comprar e cada vez mais presentes no meio online. Esses dados deram-se pela busca bibliográfica disponibilizada neste artigo.

Em campo, houve uma visão interna do site ClickOn sobre o ciclo de vida dos sites de compras coletivas, conforme proposto nos objetivos deste artigo, assim como, se fez possível uma aproximação com os usuários desse mercado por meio do questionário aplicado.

O presente estudo aponta um cenário favorável ao mercado de compras coletivas no Brasil, que no decorrer dos seus poucos mais de três anos de existência já passou por importantes modificações. Conclui-se que a essência do negócio deve permanecer, combinando promoções e desconto, mas com maior ênfase na qualidade de serviço e de atendimento. Dentro desse contexto, o ideal baseia-se na busca de saídas inovadoras que possam continuar surpreendendo os consumidores.

Sugere-se continuação e maior aprofundamento deste estudo, aumentando o número de entrevistados ao nível nacional, bem como traçar um planejamento estratégico que possa visionar cenários a esse mercado que ainda é tão novo e aparentemente oportuno.

\section{Referências}

ARAUJO, Marina. Compra coletiva oferece descontos e gera visibilidade para vendedor. Globo. 21 out. 2010. Disponível em: <http://g1.globo.com/jornal-da-globo/noticia/2010/10/ compra-coletiva-oferece-descontos-e-gera-visibilidade-para-o-vendedor.html>. Acesso em: 10 abr. 2013.

BOLSA DE OFERTAS. Brasil já tem mais de 1000 sites de compras coletivas. 2011. Disponível em < http://www. bolsadeofertas.com.br/brasil-ja-tem-mais-de-1000-sites-de-compras-coletivas/>. Acesso em: 7 maio 2013.

CASTRO, Wellington. E-commerce: vantagens para consumidores e para as empresas. 2011. Disponível em < http://www.oficinadanet.com.br/artigo/e-commerce/e-commerce--vantagens-para-consumidores-e-para-as-empresas>. Acesso em: 16 abr. 2013. 
DESTAK. Queixas contra sites de compras sobem 400\%. 23 set. 2012. Disponível em:<http://www.destakjornal.com. $\mathrm{br} /$ noticias/sao-paulo/queixas-contra-sites-de-compras-sobem-400-161579/>. Acesso em: 10 abr. 2013.

E-COMMERCE. Compra coletiva: nova estratégia de e-commerce, 2010a. Disponível em: $<$ http://www.e-commerce.org.br/compra-coletiva.php>. Acesso em: 7 maio 2013.

E-COMMERCE. Pesquisa perfil do e-consumidor brasileiro. 2012b. Disponível em: <http://www.ecommercebrasil. com.br/noticias/pesquisa-traca-perfil-do-e-consumidor-brasileiro/> Acesso em: 17 abr. 2013.

E-COMMERCE. Qual é o perfil do consumidor online? 20 mar. 2011. Disponível em: < http://www.cursodeecommerce.com.br/blog/tipos-de-consumidores-online/ > Acesso em: 17 abr. 2013.

E-MAIL Marketing. 2013. Disponível em: <http://www.e-commerce.org.br/e-mail_marketing.php $>$. Acesso em: 16 abr. 2013.

ENTREVISTA com Andrew Mason: fundador do Groupon Brasil. 4 out. 2010. Disponível em: <http://ecommercenews.com.br/artigos/entrevistas-artigos-3/entrevista-com-andrew-mason-groupon>Acesso em: 7 maio 2013.

EXAME.COM. Vendas no comércio eletrônico do Brasil devem crescer 24\%. 20 mar. 2013. Disponível em <http:// exame.abril.com.br/tecnologia/noticias/vendas-no-comercio-eletronico-do-brasil-devem-crescer-24>. Acesso em: 10 abr. 2013.

FELIPINI, Dailton. Compra coletiva. São Paulo: Brasport, 2011.

FUSCO, Camila. Sites de compras coletivas faturam US\$ 500 milhões em 2010. Folha de São Paulo. 12 dez. 2010. Disponível em: < http://wwwl.folha.uol.com.br/mercado/844527-sites-de-compras-coletivas-faturam-us-500-milhoes-em-2010.shtml>. Acesso em: 7 maio 2013.

GAZZONI, Mariana. Fechamento dos sites de compras coletivas faz setor buscar novos meios de gerar receita. 18 jun. 2012. Disponível em: <http://pme.estadao.com.br/ noticias/noticias,fechamento-dos-sites-de-compras-coletivas-faz-setor-buscar-novos-meios-de-gerar-receita,1918,0.htm>. Acesso em: 10 abr. 2013.

GIL, A. C. Como elaborar projetos de pesquisa. São Paulo: Atlas, 1991.

INFOEXAME. Compras coletivas geram $R \$ 185$ milhões de economia em dezembro. 18 jan. 2012. Disponível em < http://www.infosaveme.com.br/info/index/news/id/41>. Acesso em: 7 maio 2013.
INSTITUTO BRASILEIRO DE OPINIÃO E ESTATÍSTICA (IBOPE). Acesso à internet no Brasil atinge 94,2 milhões de pessoas. 2012. Disponível em: <http://www. ibope.com.br/pt-br/noticias/paginas/acesso-a-internet-no-brasil-atinge-94-milhoes-de-pessoas.aspx $>$. Acesso em: 10 abr. 2013.

KALAKOTA; ROBINSON. M-busness: tecnologia móvel e estratégias de negócios. São Paulo: Bookiman, 2002. p. 24.

MARTINS, Felipe. Excesso de e-mails marketing espanta consumidores. 2013. Disponível em: < http://www.administradores.com.br/artigos/marketing/excesso-de-e-mails-marketing-espanta-consumidores/70497/>. Acesso em: 21 maio 2013.

MENDES, Marcus. O comércio eletrônico no Brasil. 2010. Disponível em: $<$ http://www.ufpa.br/rcientifica/artigos_ cientificos/ed_08/pdf/marcos_mendes3.pdf $>$. Acesso em: 16 abr. 2013.

MOREYRA Sandra. Crescem reclamações contra sites de compras coletivas em todo o país. Globo. 31 jan. 2012. Disponível em <http://g1.globo.com/jornal-da-globo/ noticia/2012/02/crescem-reclamacoes-contra-sites-de-compras-coletivas-em-todo-o-pais.html >. Acesso em: 7 maio 2013.

NAKAMURA, Rodolfo. E-commerce na internet. São Paulo: Érica, 2001.

PENATTI, Geovana. Reclamações de sites de compras coletivas em 2012 superam 2011. Exameinfo. 8 ago. 2012. Disponível em <http://info.abril.com.br/noticias/mercado/reclamacoes-de-sites-de-compras-coletivas-em-2012-superam-2011-08082012-27.shl>. Acesso em: 7 maio 2013.

PINHO. J. B. Publicidade e vendas na internet: técnicas e estratégias. São Paulo: Summus, 2000.

PROGRAMA DAS NAÇÕES UNIDAS (PNDU). O Índice de Desenvolvimento Humano do Relatório de 2013 revela ganhos significativos desde 2000 na maioria dos países do Sul. 14 mar. 2012. Disponível em: <http://www.pnud. org.br/Noticia.aspx?id=3703>. Acesso em: 10 abr. 2013.

ROCHA, Karina. Convenção interna ClickOn. São Paulo: [s.n], 2013.

SCHWARTZ, Evan. Darwinismo digital. São Paulo: Makron Books do Brasil, 2000.

TORRES, Claudio. A bíblia do marketing digital. São Paulo: Novatec, 2009.

ULBRICH et. al. Guia do comércio eletrônico. Curitiba: Conectiva, 2000. 
VALLE, Alberto. Primeiro ato: sites de compras coletivas como novidade. 2011. Disponível em: <http://www.cursodeecommerce.com.br/blog/compras-coletivas-tendencias/>. Acesso em: 10 abr. 2013.

VEJA. Reclamações contra sites de compras coletivas aumentam mais de 400\%. 22 set. 2012. Disponível em: $<$ http://veja.abril.com.br/noticia/vida-digital/reclamacoes-contra-sites-de-compras-coletivas-aumentam-mais-de-400>. Acesso em: 7 maio 2013.

VELOSO, Thássius. Compra coletiva online é sucesso absoluto no Brasil. 15 out. 2010. Disponível em < http:// ecommercenews.com.br/artigos/cases/compra-coletiva-online-e-sucesso-absoluto-no-brasil >. Acesso em: 7 maio 2013. 